\title{
Initiatives to Increase Faculty Competitiveness for Federal Research Funding
}

\author{
Beth A. Montelone, Ph. D.
}

Associate Dean, College of Arts \& Sciences, Kansas State University

$\mathrm{E}$ xtramural research funding is the lifeblood of research universities, and few faculty members are unaware that competition for Federal research dollars has become ever more intense in recent years. While funding levels vary among and within agencies, the overall funding success rate for NSF was $25 \%$ in fiscal $2006^{1}$, while for NIH it was $20 \%{ }^{2}$. These compare with historical averages in the thirtypercent range during the $1990 \mathrm{~s}^{1,2}$. Figures 1 and 2 show that part of the reason for this drop is that the numbers of applications received by both agencies have increased substantially during the last ten years, while the number of awards made by each has stayed relatively flat. This is true despite the doubling of the NIH budget over the period 1998-2003.

The current budget situation does not suggest that the availability of grants will be changing soon; the President has proposed to increase some programs at NSF and $\mathrm{DOE}^{3}$ but his science advisor has stated that scientists should not expect large influxes of money into other programs ${ }^{4}$. NIH director Elias Zerhouni also does not envision an improvement in the availability of traditional investigator-initiated awards, but points to a need to preserve future generations of scientists through programs to support new investigators via new grant programs and mentoring 5 . An example that NIH has already launched is the Pathway to Independence Award program, to which scientists still in postdoctoral positions can apply. If funded these individuals are eligible for two years of training support with a mentor and three years of funding in their first faculty position ${ }^{6}$.

\section{Kansas State University programs to} develop new investigators

Kansas State University (K-State) has created or participates in a series of initiatives with primary or secondary goals of providing mentoring and/or resources to assist new faculty members in establishing the successful research programs necessary to achieve tenure. Collectively, these contribute to a nurturing atmosphere in the science and engineering departments at K-State. Several of these and their outcomes to date are described below.

\section{Center of Biomedical Research Excellence} (COBRE) in Epithelial Health and

\section{Disease}

The NIH-funded COBRE award to

Dr. Daniel Marcus of the Department of 
Anatomy \& Physiology in the College of Veterinary Medicine (CVM) began in 2002. This project was intended to enhance the careers of junior faculty members, both basic researchers and clinician-scientists, at K-State and other Kansas institutions. It provides seed funding to the junior faculty and establishes a partnership with a mentor, with the goal of making the junior faculty competitive for independent $\mathrm{NIH}$ funding. The theme of this COBRE is epithelial function in health and disease; its associated projects center on epithelial cell physiology or pathophysiology and provide a strong foundation for translational research.

The COBRE is comprised of seven teams of junior faculty members and mentors in the CVM and collaborating departments at K-State, the University of Kansas Lawrence campus, and the University of Kansas Medical Center. These individuals, along with the COBRE Director and advisory committee members, participate in a structured program of interdisciplinary interactions in video-conferenced seminars. The COBRE award also established three core facilities to support the research of participating faculty at K-State. These include a stateof-the-art confocal microscope facility; a molecular biology support facility; and an epithelial electrophysiology facility.

Outcomes of the COBRE: Over the last 5 years, COBRE participant progress resulted in 54 publications, and 218 presentations and abstracts related to COBRE activities ${ }^{7}$. Six junior faculty members have successfully "graduated" out of the program and are now tenured. A research community focusing on epithelial cells has emerged from the interactions promoted by the center. Extramural funding, particularly among investigators in the CVM Department of Clinical Sciences, has shown gratifying improvements in success rate and total dollars awarded since the start of the COBRE (see Table 1).

Kansas Idea Network of Biomedical Research Excellence (K-INBRE)

$\mathrm{K}-\mathrm{State}$ is a partner in this program, which is hosted at the University of Kansas Medical Center. It is funded through the National Institutes of Health Center for Research Resources for the purpose of strengthening biomedical research and training researchers in cell and developmental biology in the state of Kansas. Its aims include building a research network, increasing the research base by providing support to junior faculty, postdoctoral fellows, and graduate students, encouraging undergraduate participation in research, and enhancing the research infrastructure in the bioinformatics area. The K-INBRE program has made Faculty Scholar Awards, Starter Grants, and Pilot and Bridging Awards to faculty members from K-State and other KS campuses.

\section{Targeted Excellence}

The K-State Targeted Excellence project is funded through the K-State Provost's Office from tuition monies. It was created in 2003 and is intended to "enhance those programs (primarily inter-disciplinary) with the most promise of elevating the university's stature."8

There have been four rounds of competition to date. The program considers cross-departmental projects 
that involve multi-disciplinary themes or ideas, projects that may vary in length from short-term (one to two years) to long-term (up to five years), and requests from $\$ 50,000$ to $\$ 2,000,000$. A total of 26 distinct projects have been funded in the first four competitions, some for relatively small amounts to initiate projects (ca. $\$ 100,000$ ) and other large collaborative awards receiving \$2M over multiple years. These major awards established new research centers and provide seed funding to stimulate innovative and collaborative research, and provide an important university resource for encouragement, support, and mentoring of junior faculty members. Some of these centers are described below.

The Ecological Genomics Institute brings together scientists using cellular and molecular biological approaches with those interested in ecological and evolutionary questions to create new cutting edge research and synergize interactions across colleges and departments. Part of their funding has been used as start-up for hiring two new faculty members and has supported initial research projects by other individuals and teams.

The Center for Genomic Studies on Arthropods Affecting Human, Animal, and Plant Health builds on expertise of faculty members in Agriculture, Arts \& Sciences, and Veterinary Medicine who work on a variety of areas including insect developmental genetics, biochemistry, animal disease, and plant disease. It will build capacity in genomics and bioinformatics through personnel hires and equipment purchases. New faculty members are supported through a seed grant mechanism and the establishment of collaborative work groups.

The Center for Bio-based Polymers by Design fostered collaborations between new faculty and established researchers in the biomaterials area, including investigators from several engineering disciplines, biochemistry, chemistry, physics, and grain science. This group is in the process of submitting a proposal to NSF for a Materials Research Science and Engineering Center award, which would support graduate students, postdoctoral scientists, and junior investigators.

A recent summary of funding garnered by the projects supported by Targeted Excellence showed that $\$ 14.2 \mathrm{M}$ in extramural grants have been leveraged by the investigators associated with these projects (J. Guikema, personal communication). This compares favorably to a university investment of $\$ 15.5 \mathrm{M}$ for projects funded in the first three years. Since some of the projects included were underway less than a year when this accounting was done, it suggests that this investment will be profitable for the university over the long term.

\section{K-State Mentoring Program}

The KSU Mentoring Program for Women and Minority Faculty in the Sciences and Engineering was created in 1993 with a grant from Sloan Foundation. It requires junior faculty members to identify a mentor in their discipline and provides small (\$6000) awards that can be used for a variety of purposes. Since 1999, funding has come from the office of the K-State Vice Provost for Research using grant indirect 
costs as the source. Eligibility is limited to tenure-track female and minority faculty in science and engineering who have not yet been principal investigator on a major extramural grant. The purpose is to provide junior faculty with mentors in their research areas who will help them achieve extramural funding, the first step necessary for tenure and success in science and engineering departments.

The program at its conception did not specify limitations on use of program funds and as it has evolved, broad guidelines have been developed that provide a great deal of flexibility to applicants. The most common requests include seed money for research supplies and assistants, professional travel, and attendance at short courses. Proposals that ask only for faculty or graduate assistant salary must be justified in terms of how they will professionally benefit the applicant. All proposals require a short description of activities in non-technical language, a detailed budget request, a listing of current and pending support, a description of the planned mentormentoree relationship with curricula vitae for each, and a letter of commitment from mentor.

Recipients of the mentoring fellowship are required to report to the Provost's Office on outcomes of the experience, including how the funding and mentoring relationship benefited them. A 2003 report on the program ${ }^{9}$ included the information that the funding was used to obtain preliminary data, "jump-start" research projects, engage in professional travel to enhance research, and that the mentoring relationships so established continued following the award period. In some cases, mentoring relationships established as a result of the proposal submission went forward even if the proposal not funded.

To date, 57 individuals have received awards (11 women of color; 6 men of color); of these, 43 have received significant extramural funding to date. Of 32 faculty members who have become eligible, 25 have received tenure $(78 \%)$, and 20 of these are still at K-State. Seven female recipients were promoted through the ranks to full professor since receiving their awards. An estimate for our 2003 paper showed that at that time, the extramural funding generated by the mentoring award recipients had provided over a one-hundred fold return on investment in the program. The tenure and retention data are higher than the overall average for science and engineering disciplines as well (unpublished data from K-State ADVANCE Project).

\section{K-State ADVANCE Institutional Transformation}

K-State received a $\$ 3.5 \mathrm{M}$ Institutional Transformation Award from NSF in 2003. This five-year project, supported by the ADVANCE program, is intended to effect changes in practices, policies, and procedures that promote an equitable environment in which both male and female faculty members in science and engineering can thrive and succeed. Some of the mentoring, networking, and professional development programs created by ADVANCE provide funding to support individual women faculty, while others are aimed at changing institutional 
practices $^{10}$. The former can serve as models that are eventually adopted across the university. Some of these are described below.

The ADVANCE Distinguished Lecture Series is more than a seminar series, although that is the vehicle that was chosen. It was intended to help develop the professional network of junior women faculty and diffuse the effects of being isolated as the only woman in a department and geographic isolation in Manhattan. It provides $\$ 1200$ awards to support seminar visits by national leaders in a junior woman's professional discipline. These awards are competitive and must be justified and approved by the project Steering Committee. This program has had excellent levels of participation and outcomes to date, some of which have been reported elsewhere ${ }^{11}$. Participants report that they have made substantive connections with prominent scientists and engineers from prestigious universities, government agencies, and private industry. The seminar hosts received valuable advice on grant proposals and publications, initiated collaborations, and have been invited for reciprocal visits to their guests' institutions. The ADVANCE leadership team is now working with the KSU Foundation to identify funding sources to institutionalize the program following the end of federal funding.

Parallel Paths is a peer group mentoring program in College of Veterinary Medicine. It was designed to foster the development of junior faculty members, sustain the productivity of established faculty members, and create an environment to help all participants succeed in their teaching, research, clinical, and service roles. Groups are open to both female and male faculty members. They hold monthly dinner meetings to discuss issues and concerns of junior faculty and have organized faculty development workshops. The dinner and workshop topics have included gender and other diversity issues; aspects of teaching and research, graduate student and resident training; work/life balance; and career advancement. Funds allocated to the program have been used to support faculty development. Outcomes over the last three years have been assessed by reports, surveys, and focus groups. Participants have reported benefits such as increased collegiality; enhanced crossdepartmental dialogue; opportunities to learn about other faculty members' research interests; and an improved understanding of the promotion and tenure process ${ }^{12}$.

Each participating college in the ADVANCE Project has created a program that supports the research programs of junior women faculty by providing seed money as well as funds for travel to conferences, funding agencies, etc. The project will be collecting information on whether seed funding has resulted in extramural grants, initiation of collaborations, and increased rates of tenure.

The Career Advancement Program is open to tenured women in all four colleges and addresses the transition from associate to full professor as well as providing opportunities for women interested in administration to gain experience in this area. Focus groups will be used in addition to quantitative 
outcomes to measure the success of this program.

The ADVANCE Project is in its fourth year. While it is difficult to identify metrics to measure institutional transformation, the early results show impressive increases in numbers of women faculty and increases in the ranks of tenured and full professor women in science and engineering ${ }^{13}$.

\section{Collaborative for Outreach, Recruitment,} and Engagement in STEM (Science,

\section{Technology, Engineering, and}

\section{Mathematics) (CORES)}

The CORES project, which is funded by Targeted Excellence, unlike the other programs described above does not provide direct mentoring or funding for junior faculty members. Instead, it links science/engineering-based K-12 outreach and undergraduate research/ engagement programs, including those aimed at women and underrepresented minority students. Its goals are to synergistically enhance all of its constituent programs, facilitate recruiting and tracking of students, recruit students to K-State undergraduate and graduate programs, and to institutionalize and facilitate "broader impact" activities for K-State faculty preparing grant proposals.

The importance that Federal agencies are now placing on broader impact aspects of research proposals is illustrated by the recent call by NSF for chemistry multiuser instrumentation proposals ${ }^{14}$. This program, which is a vehicle for expanding the capabilities of investigators by providing expensive multi-user instrumentation to departments, now requires as part of the proposal, a statement of how acquisition or upgrade of the requested instrumentation will fit the departmental plan for broadening participation. The departmental plan itself must be submitted as a supplement to the proposal.

\section{Summary}

Kansas State University has recognized the need to cultivate junior faculty members by providing them financial resources and a supportive climate in order to enable them to become established extramurally funded researchers. Our programs, including the COBRE in Epithelial Health and Disease, Targeted Excellence, K-State Mentoring, ADVANCE, and CORES, are funded by a combination of extramural and internal sources. Return on investment data, where available, suggest that these are monies well spent. Future research at the level of the institution and the individual projects will continue to focus on the financial aspects and also will examine the impacts of such programs on tenure and retention of faculty.

\section{References}

1. NSF Budget Internet Information System. Accessed at http://dellweb.bfa.nsf.gov/awdfr3/default.asp

2. NIH Office of Extramural Research. Success rates by Institute. Accessed at: http://grants.nih.gov/grants/award/success/Su ccess_ByIC.cfm

3. Mervis, J. Research rises - and falls - in the President's spending plan. Science 315: 750753. 2007.

4. Mervis, J. Science adviser says the pruning is the key to a healthy budget. Science 315: 927, 2007.

5. Zerhouni, E.A. NIH in the post-doubling era: realities and strategies. Science 314: 1088-1090, 2006.

6. NIH Pathway to Independence Award (K99/R00). Accessed at: 
http://grants.nih.gov/grants/guide/pafiles/PA-07-297.html

7. Center for Epithelial Function in Health and Disease. Program Overview. Accessed at http://www.vet.kstate.edu/depts/ap/COBRE/overview.htm

8. K-State Targeted Excellence Program Guidelines. Accessed at: http://www.kstate.edu/provost/planning/targetexc/proposal s.htm

9. Montelone, B. A., R. A. Dyer, and D. J. Takemoto. A mentoring program for female and minority faculty members in the sciences and engineering: effectiveness and status after nine years. J. Women Minor. Sci. Eng. 9: 259-271, 2003.

10. K-State ADVANCE Institutional Transformation. Accessed at http://www.ksu.edu/advance

11. R. A. Dyer and B. A. Montelone. “An institutional approach to establishing professional networks." In: Transforming Science and Engineering, A. J. Stewart, J. E. Malley, and D. Lavaque, eds, Ann Arbor: University of Michigan Press; pp. 48-61, 2007.

12. R. A. Dyer, B. A. Montelone, and B. R. Rush. Parallel Paths: A college-wide peer group mentoring program. WEPAN 2007 National Conference Proceedings, Lake Buena Vista, FL, 2007. Available online at: http://www.xcd.com/wepan07/WEPAN2007_0014.pdf

13. ADVANCE Reports and Progress. Accessed at: http://www.kstate.edu/advance/ReportsProgress/reports.ht $\mathrm{ml}$

14. NSF 07-552: Chemistry Research Instrumentation and Facilities: Departmental Multi-User Instrumentation. Accessed at: http://www.nsf.gov/publications/pub_summ.j sp?ods_key=nsf07552 


\section{Applications, Awards, Funding Rate-NIH}

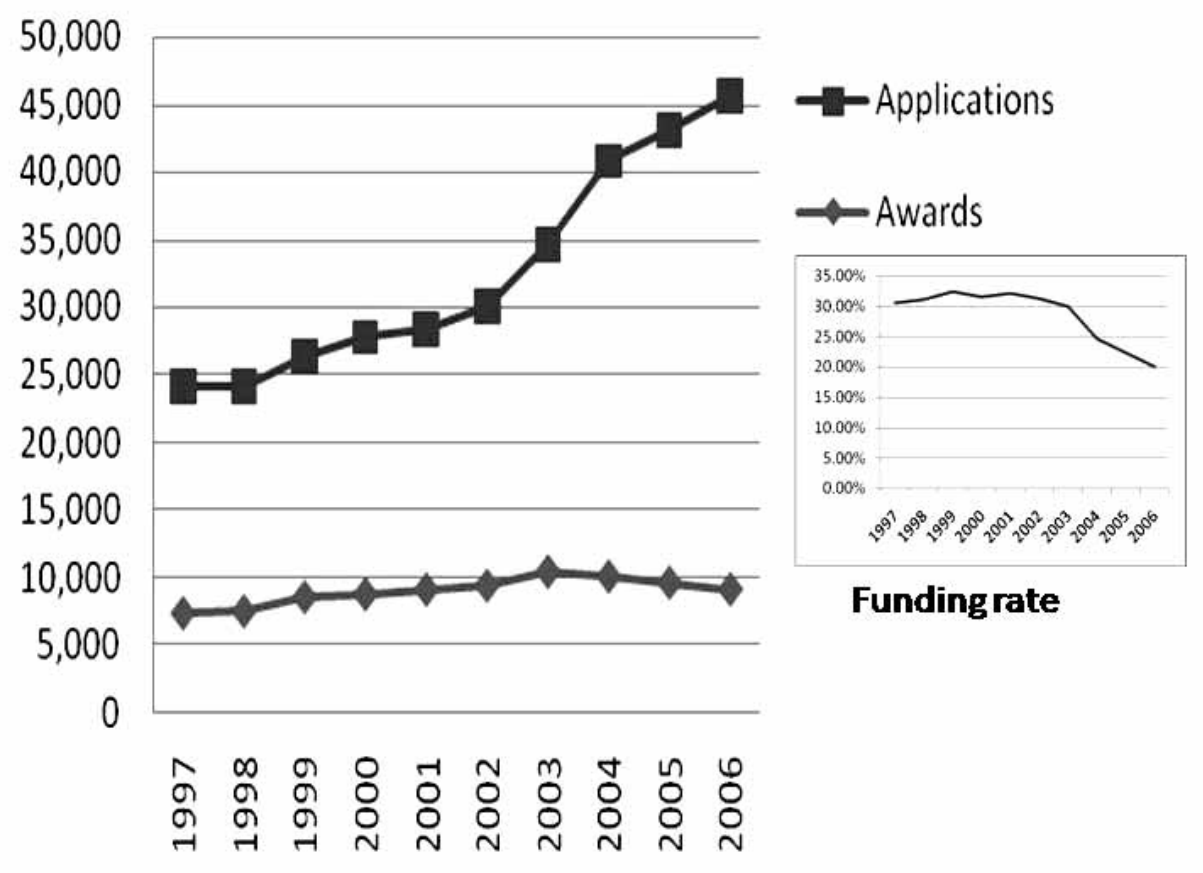

Figure 1. Applications for grants, awards made, and funding rate, all NIH institutes. Source -reference 2. 


\section{Applications, Awards, Funding Rates-NSF}

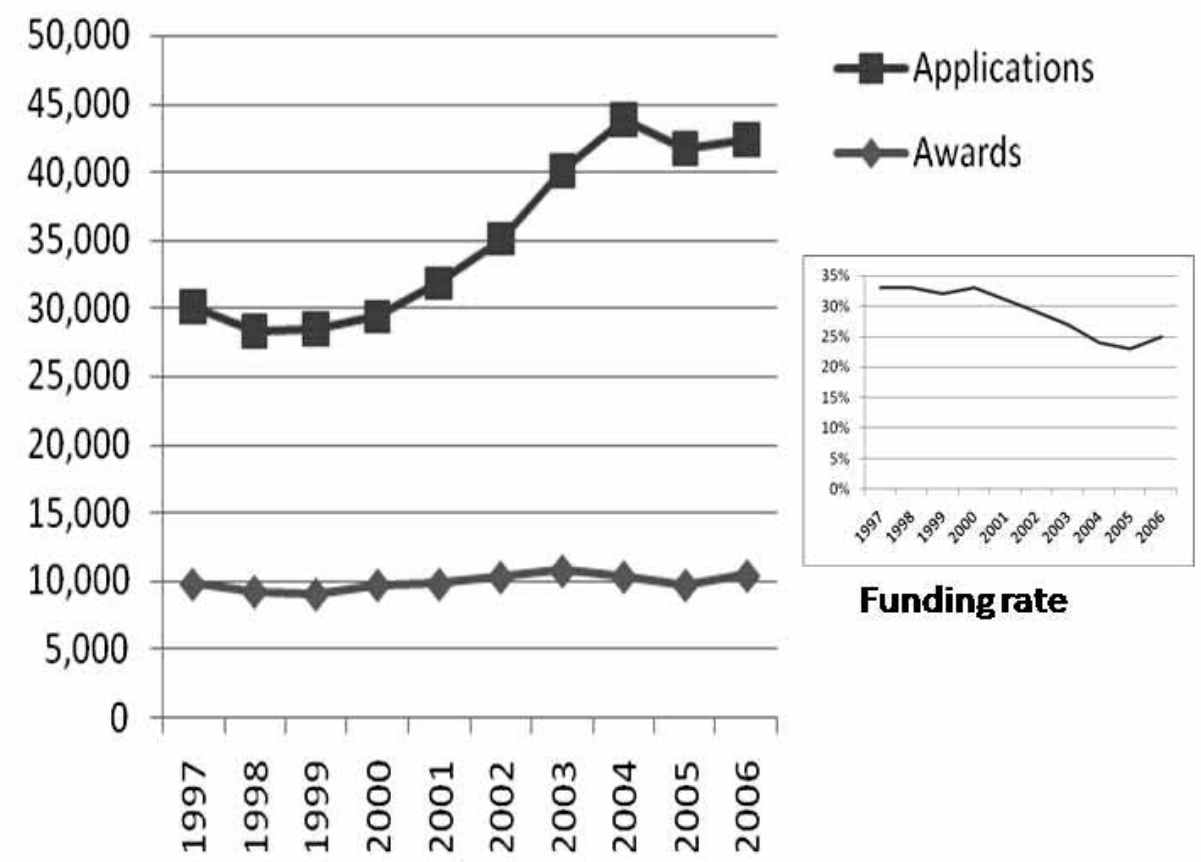

Figure 2. Applications for grants, awards made, and funding rate, all NSF programs. Source -reference 1.

Table 1. Funding success in K-State Department of Clinical Sciences

\begin{tabular}{|l|l|l|}
\hline & $\mathbf{F Y 0 4}$ & FY06 \\
\hline \# Proposals & 30 & 32 \\
\hline \$\$ Proposals & $\$ 3,104,499$ & $\$ 3,202,946$ \\
\hline \# Awards & 14 & 23 \\
\hline \$\$ Awards & $\$ 446,741$ & $\mathbf{\$ 1 , 3 8 5 , 4 6 8}$ \\
\hline
\end{tabular}

Source: Dr. Lisa Freeman, Associate Dean of the College of Veterinary Medicine 